\title{
GILLICK AND THE CONSENT OF MINORS: CONTRACEPTIVE ADVICE AND TREATMENT IN NEW ZEALAND
}

\author{
Tim Grimwood
}

\begin{abstract}
The English House of Lords decision in Gillick has dominated the issue of minor capacity to consent for the last 25 years, but the decision has raised more issues and ambiguities than it hoped to solve. The speeches in Gillick, although extrapolated to general issues of minor consent, were made in the context of contraception advice and treatment. In New Zealand there is no legislation or case law determining if and when minors can obtain contraception advice and treatment without parental consent or knowledge. This raises concerns for health professionals' practice and minors' status as patients. This article discusses whether the rulings in Gillick are applicable or even should be applicable to New Zealand with regards to contraception. The article suggests a scheme for giving contraceptive advice and treatment to minors through a modification of Lord Fraser's guidelines. These modifications have been incorporated into a suggested legislative framework and professional guidelines.
\end{abstract}

\section{INTRODUCTION}

In 1985 in England, Mrs Gillick took the Department of Health and Social Services to court over guidelines it issued regarding family planning. The guidelines stated that in some cases a health professional could be justified in prescribing contraceptives to an under 16 year old without parental consent. She argued that in the best interests of her children she should be fully informed and have to consent on their behalf. The final decision in Gillick $v$ West Norfolk Area Health Authority (Gillick) came from the House of Lords. ${ }^{1}$ There, the majority affirmed the issued guidelines and Lord Scarman and Lord Fraser, specifically, set out their own competency guidelines for when a child under 16 years could expect to receive contraceptive advice and treatment without parental consent or knowledge.

* Submitted as part of the LLB(Hons) programme at Victoria University of Wellington. I would like to acknowledge the invaluable assistance and enthusiasm of Professor Bill Atkin.

1 Gillick $v$ West Norfolk Area Health Authority [1986] 1 AC 112 (UKHL) [Gillick]. 
Several common law jurisdictions readily adopted the House of Lords ruling, giving rise to a generic Gillick competency test for children. In New Zealand, a situation inviting the adoption of the ruling has never arisen, although the principles that the decision was founded on have been adopted in a rather ad hoc fashion in case law, legislation and academia. This adoption, however, has not adequately addressed whether Lord Scarman's or Lord Fraser's guidelines is most applicable to New Zealand, nor how to deal with the flaws inherent in each competency guideline. Therefore, if a Gillick situation arose in New Zealand the courts would be working in a very grey and illdefined area, and health professionals with an ethically challenging set of principles regarding competency for under 16 year olds.

This article discusses the suitability of the majority Gillick judgment to New Zealand law. First, the current legal situation with regard to capacity to consent to contraceptive advice and treatment of under 16 year olds will be considered. Second, with regard to this obvious hole in New Zealand law, whether the competency tests in Gillick can or even should be applied to New Zealand is investigated. Further issues arising from Gillick, those of confidentiality and refusal to consent, will then be discussed. The article ends with a discussion and recommendations on the actual specifics of a Gillick type competency test.

For the purposes of this article the terms 'minor' and 'child' both refer to persons under 16 years of age.

\section{NEW ZEALAND LAW WITH REGARD TO MINORS AND CONTRACEPTION}

Except in emergency or very unusual circumstances, health professionals cannot treat any individual without authorised consent for fear of common law battery or negligence liability. ${ }^{2}$ In New Zealand, legislation further dictates that anyone over 16 can refuse or consent to medical treatment as if they were of full legal age, ${ }^{3}$ which is attained at $20 .{ }^{4}$ However, there is no statutory

2 A medical or surgical procedure without consent is common law trespass to the person and the giving of medical advice or non-invasive treatment without consent is negligence. A person can receive medical treatment without informed consent, for example under the Mental Health (Compulsory Assessment and Treatment) Act 1992, the Tuberculosis Act 1948, s 7(2)(a) - compulsory treatment if diagnosed as having TB and the Health Act 1964, s 88(1) - compulsory treatment if person has or is suspected of having venereal disease.

3 Care of Children Act 2004, s 36(1):

(1) A consent, or refusal to consent, to any of the following, if given by a child of or over the age of 16 years, has effect as if the child were of full age:

(a) any donation of blood by the child:

(b) any medical, surgical, or dental treatment or procedure (including a blood transfusion, which, in this section, has the meaning given to it by section $37(1)$ ) to be carried out on the child for the child's benefit by a person professionally qualified to carry it out. 
guidance on consent or refusal to consent of minors. Further, the statutory guidelines regarding who can give contraceptive treatment and advice to minors have been repealed, ${ }^{5}$ leaving no specific statutory guidance on when, how and in what circumstances a health professional can give contraceptive advice or treatment to a minor without parental consent or knowledge. As well as guidance from the New Zealand Medical Association Code of Ethics and the Code of Health and Disability Services Consumers Rights, health professionals also consider, that, as the law allows a minor to consent or refuse to consent to a termination of pregnancy, ${ }^{6}$ a significant decision which does not require parental consent or knowledge, then giving advice or treatment on contraception without parental consent or knowledge can be seen as justifiable. ${ }^{7}$

Implying law from what statutes say or do not say is an imprecise exercise and in reality what New Zealand has is a statutory blackhole creating a significantly deregulated area. However, the common law picks up the pieces and in this case, the House of Lords' decision of Gillick.

\section{THE COMMON LAW OF GILLICK}

\section{A Gillick and New Zealand}

Two cases have come close to openly declaring that Gillick does apply to New Zealand. In Re $S P O$, Judge Ullrich declared, after quoting Lord Scarman's famous "sufficient understanding and intelligence" speech as discussed below, that "[t]his principle has become known as the Gillick principle and has been applied to New Zealand." ${ }^{8}$ In Hawthorne v Cox, Heath J explained s 16(1) of Care of Children Act 2004, stating that as a child grows in age and maturity, a guardian's role "changes to that of an adviser or a counsellor, endeavouring to assist the child to make good decisions." Put in those terms, the legislation is consistent with the philosophy underpinning

4 Age of Majority Act 1970, s 4 .

5 Contraception, Sterilisation and Abortion Act 1977, s 3 was repealed by the Contraception, Sterilisation and Abortion Amendment Act 1990, s 2 .

6 Care of Children Act 2004, s 38:

(1) If given by a female child (of whatever age), the following have the same effect as if she were of full age:

(a) a consent to the carrying out on her of any medical or surgical procedure for the purpose of terminating her pregnancy by a person professionally qualified to carry it out; and

(b) a refusal to consent to the carrying out on her of any procedure of that kind.

(2) This section overrides section 36

7 Conversation with Helen Colebrook, in an individual capacity, as former New Zealand College of General Practitioners' principal Policy advisor, former Health and Disability Commissioner employee and former Chair of central regional ethics committee (29 April 2010).

$8 \quad \operatorname{Re}$ Spo FC Wellington FAM 2004-085-1046, 3 November 2005 at [25]. 
Gillick, namely that a parent's interest in the development of their child does not amount to a "right" but is more accurately described as "a responsibility or duty". 9

However, in both cases, little thought was given as to what Gillick competence actually is. What is the standard? Should it be applied to refusal to consent as well as consent and in what circumstances should it be applied? Heath J used Gillick as the common law recognition of the change in parental roles, as minors age and mature. In Re SPO Judge Ullrich decided that a boy of 15 who wanted to finish a course of MENZ B vaccinations, against his mother's wishes, had "sufficient understanding and intelligence to be capable of making his own mind up" as he had discussed the issue with a public health nurse, general practitioner and older brother. ${ }^{10}$ However, Judge Ullrich did not examine the boy's actual understanding of the treatment or his capacity to understand in terms of Gillick, just that he had received relevant information.

The High Court of Australia openly adopted Gillick as part of its common law, but, similar to New Zealand, the Court did not give any specifics about what Gillick competence actually is and when or how it is to be used. In that instance, the Court did not need to explore Gillick further as the subject of the litigation was, at the time, clearly incompetent due to severe mental and behavioural handicap. ${ }^{11}$

Many authors have also fallen into this trap. They recognise that a minor's growing autonomy needs to be recognised with regards to consenting to medical treatment and have advocated the use of Gillick competency, but have not considered the actual suitability of the tests, which of the tests should be used and what the tests actually embody. ${ }^{12}$

\section{SHOULD GILLICK BE ADOPTED IN NEW ZEALAND?}

For Gillick to be adopted in New Zealand there are several issues that need to be addressed and clarified. Flaws specific to the individual tests of Lord Scarman and Lord Fraser will be discussed. Whilst discussing these issues the suitability of these tests to New Zealand will be addressed and

9 Hawthorne v Cox [2008] 1 NZLR 409 (HC) at [60]-[61]. The case describes a guardianship issue that the mother was too controlling and had lost guardianship rights due to the Family Court decision. The appeal to the High Court was to get those rights re-instated.

10 Re Spo, above n 8, at [27].

11 Secretary, Department of Health and Community Services v JMB and SMB (1992) 15 Fam LR 392 (HCA) at [401] [Re Marion].

12 For example, Morag McDowell "Medical Treatment and Children: Assessing the Scope of Child's Capacity to Consent or Refuse to Consent in NZ" (1997) 5 JLM 90, she recommends the adoption of Gillick in terms of the principles of increasing autonomy without analysing the nitty gritty of what the judges expected of the minors and the caveats placed on competent minors. Terence Bartholomew and Tatiana Carvallo "General Practioners' Competence and Confidentiality Determinations with a Minor who Requests the Oral Contraceptive Pill" (2005) 13 JLM 191, describe and analyse the adoption of Gillick competency in Victoria, Australia. 
conclusions on the question if or how Gillick can be applied. The issues of confidentiality and refusal to consent, although receiving little comment in the Gillick judgment, need to be analysed in relation to Gillick, as they are vital issues to the acceptability of a competency test in New Zealand.

\section{A Issues Specific to each Gillick Test}

\section{Lord Scarman's Test}

Lord Scarman's test describes how the rights of the parents over the child decline as the child increases in understanding and maturity: ${ }^{13}$

... the parental right to determine whether or not their minor child below the age of 16 will have medical
treatment terminates if and when the child achieves a sufficient understanding and intelligence to enable
him or her to understand fully what is proposed.

The words in italics represent what is commonly called Gillick competence.

Although Lord Scarman's test initially appears clear, the practicability of the test is strained by the qualification he puts on it. According to Lord Scarman's qualification, to be deemed competent to make a decision regarding contraception without parental consent or knowledge, a minor must fully understand the moral, emotional and familial, long, and short-term implications of the decision. ${ }^{14}$ This has been regarded as a very high threshold and has been called an ability to exercise a "wise choice"15 and one that medical doctors have expressed as higher than they would expect from some competent adults. ${ }^{16}$ One of the issues with this very high threshold is that often "the least intelligent girls [are the ones] who are the most vulnerable and therefore need protection of contraception". ${ }^{17}$

Another issue is that in New Zealand parents can exclude their children from sex education, ${ }^{18}$ and so if the competency test for a minor to gain contraceptive advice from a health professional without parental consent or knowledge is too high, for many who actually need the advice, this could promote risky sexual behaviour.

13 Gillick, above n 1, at [189] per Lord Scarman.

14 Ibid.

15 Patrick Parkinson "Children's Rights and Doctors' Immunities: The Implications of the High Court's Decision in Re Marion" (1992) 6 AJFL at 111.

16 Diana Brahams "The Gillick Case: A Pragmatic Compromise" (1986) 136 NLJ 75 at 76; New South Wales Law Reform Commission Report 199: Young People and Consent to Health Care (Sydney, 2008) at 82.

17 Brahams, above n 16 , at 77.

18 Education Act 1989, s 25AA. 
Equally, if minors do not have access to prescription contraception, again due to the threshold of the assessment of their competence being too high, and they do not want to involve their parents, then they will be subject to much less effective contraceptive methods. ${ }^{19}$ For example, minors will be vulnerable to situations of having to use over-the-counter contraception such as condoms, which have a significantly higher failure rate among adolescents than older adults, due to sexual inexperience. $^{20}$ This is further augmented by the embarrassment of obtaining contraception, the inherent power imbalance men have over women, which can preclude condom use, ignorance and immaturity to assert contraceptive necessity and stigma of promiscuity if girls carry condoms. ${ }^{21}$

\section{LORD FRASER'S GUIDELINES}

Lord Fraser's guidelines describe the steps a health professional should go through to determine whether to give contraceptive advice or treatment to a minor without parental consent: ${ }^{22}$

... provided he is satisfied on the following matters: (1) that the girl (although under 16 years of age) will understand his advice (2) that he cannot persuade her to inform her parents or to allow him to inform the parents that she is seeking contraceptive advice (3) that she is very likely to begin or to continue having sexual intercourse with or without contraceptive treatment (4) that unless she receives contraceptive advice or treatment her physical or mental health or both are likely to suffer (5) that her best interests require him to give her contraceptive advice, treatment or both without the parental consent.

Similar to Lord Scarman's test, the guidelines at first blush appear straightforward, and perhaps more practically applicable than Lord Scarman's test. However, their adoption in New Zealand would have difficulties in at least two of the steps.

(a) Step one of the guidelines

In step one the level of understanding the minor is required to have of the contraceptive advice is not qualified in the actual guidelines. There is nothing in Lord Fraser's speech to suggest that he agreed with the qualifications of Lord Scarman. It appears Lord Fraser set the bar lower, as during

19 For example, the typical user failure rate of the combined or mini contraceptive pill is eight per cent whereas for condoms it is fifteen per cent. The actual product failure rate of the latter is 0.3 per cent and the former is two per cent. National Collaborating Centre for Women's and Children's Health Long-acting Reversible Contraception: The Effective and Appropriate Use of Long-acting Reversible Contraception (RCOG, London, 2005) at 23.

20 M Preboth "Use of Oral Contraception Among Adolescents" (2000) 61 Am Fam Physician, 3225. Cited in Terence Bartholomew and Tatiana Carvallo "General Practioners' Competence and Confidentiality Determinations with a Minor who Requests the Oral Contraceptive Pill" (2005) 13 JLM 191 at 193.

21 Jan Browne and Victor Minichiello "The Condom: Why more People don't put it on" (1994) 16 Sociology of Health and Illness 229 at 235-248.

22 Gillick, above n 1, at 174 Lord Fraser. 
his speech he remarked that a minor is competent "[p]rovided the patient, whether a boy or a girl, is capable of understanding what is proposed, and of expressing his or her own wishes". 23 This sets a much more realistic standard than Lord Scarman's qualification. However, similar to Lord Scarman, there is ambiguity as to whether actual understanding of the proposed treatment or the capacity to understand the proposed treatment is the competency test, and further what is the threshold of that understanding.

(b) Step five of the guidelines

In step five of Lord Fraser's guidelines, the doctor must be satisfied that giving contraceptive advice and treatment without parental knowledge or consent is in the minor's best interests. ${ }^{24}$ Lord Scarman, as did Lord Fraser, dictated that the doctor must first try and persuade the girl to include her parents in the decision-making process. ${ }^{25}$ However Lord Scarman made no mention of the doctor having a discretionary best interests veto. The doctor's sanction to veto a competent minor's decision in Lord Fraser's guidelines is fundamentally different from the respective increasing and decreasing rights approach of maturing children and guardians taken by Lord Scarman. Lord Scarman surely did not intend parental rights to be terminated and replaced by that of an assessing doctor? ${ }^{26}$ After all, the freedom to decide must include the right to make a less than perfect or rational decision. As Lord Scarman said, the properly construed consent enables the doctor to legally proceed with the contraception advice, ${ }^{27}$ not the power to veto it.

Further, Lord Fraser confused the best interests issue in his speech; step five gives a doctor the power to veto a minor's decision in preference for what the doctor believes is in the best interests of that minor. However, he also stated, earlier in his speech, that the question of a minor's consent to contraception is one "of fact for the judge (or jury) to decide". ${ }^{28}$ This produces an uncertain situation whereby a doctor may be forced to adopt defensive medicine in such cases, as a judge or jury may find fault with the doctor's best interests reasoning. Therefore, who actually has the legal right to decide whether advice and treatment is in the best interests of the child needs to be clarified before the issue comes to court. ${ }^{29}$ This is for the protection of the health professional and would not affect the wardship jurisdiction of the court from over-riding the health professional's decision.

\footnotetext{
23 Ibid, at 169 per Lord Fraser.

24 Ibid, at 174

25 Ibid, at 189 Lord Scarman.

26 Ibid.

27 Ibid.

28 Ibid, at 172 per Lord Fraser.

29 Parkinson, above $\mathrm{n} 15$, at 107
} 
For New Zealand to adopt Lord Fraser's guidelines, although the competency standard is much more realistic and practical than Lord Scarman's, step one would need to spell out what "understanding the advice" actually entails. Further, the best interests element would need to be clarified: does the doctor have the power to veto the child's decision if deemed competent or can the finders of fact deem the doctor's assessment faulty? Lord Fraser's guidelines look more promising than Lord Scarman's for contraceptive advice in New Zealand, as the threshold for competency is essentially left open by Lord Fraser and so a suitable level could be determined. However, the best interests veto is a large stumbling block and one that the courts have struggled with. It will be more fully discussed below.

\section{BEST INTERESTS}

Since Gillick, the welfare of the minor has been the dominant concern of the courts in questions of medical treatment. Two cases in particular stand out where the English Court of Appeal overrode probably Gillick competent children who refused blood transfusions due to their religious beliefs.

\section{$A \operatorname{Re} \mathbf{E}$ and $\operatorname{Re} \mathrm{L}$}

In $R e E$ the subject of the case was a 15-year-old boy who needed blood transfusions for leukaemia treatment. Being a Jehovah's Witness he refused treatment, supported by his family. ${ }^{30}$ Although Ward J deemed the boy intelligent enough to make his own decisions, he believed the boy was not able to understand the pain, fear and suffering he and his family would suffer as he neared death and therefore was not competent to make the decision to refuse treatment. ${ }^{31}$ Although it could be argued that Ward J was using Lord Scarman's "wise" decision to assess the boy and therefore was assessing him to a threshold few competent adults could reach, the tone of Ward J's judgment rather reflects his priority to protect the boy from himself and his parents. ${ }^{32}$

In $R e L$, the subject was a 14-year-old girl, again a Jehovah's Witness, who refused a blood transfusion after suffering horrific burns. The judge decided she was not Gillick competent, as the adults around her, including the doctors, parents and the judge, had deemed it inappropriate for her to be fully informed of how awful her death would be. ${ }^{33}$ It was therefore impossible for her to be Gillick competent, leaving the court to decide, that her strong belief and limited experience required the court to intervene to preserve her best interests.

30 Re E (A Minor) (Wardship: Medical Treatment) [1992] 2 FCR 219 (CA) at [221] [Re E].

31 Ibid, at 224.

32 Ibid, at 227.

33 Re L (Medical Treatment: Gillick Competency) [1992] 2 FCR 524 (CA) at [527] [Re L]. 
In these two cases the court was, in reality, not testing the capacity of the children but was testing the actual decisions they made. The rationality or irrationality of their decisions decided their fate as the court took protection over them. This protection of the court is the court's wardship jurisdiction which is "essentially parental jurisdiction where the court would do what in the circumstances a wise parent acting for the true interests of the child would or ought to do". ${ }^{34}$ The wardship jurisdiction of New Zealand courts comes from two sources, an ancient common law jurisdiction of the High Court, which was adopted into New Zealand by the Judicature Act $1908,{ }^{35}$ and a statutory jurisdiction of the Family and High Court. ${ }^{36}$

Even if the two minors in the above cases were not Gillick competent as the judges determined, Lord Donaldson firmly believed that the wardship jurisdiction of the court could over-ride the wishes of a Gillick competent minor. ${ }^{37}$ It has been argued that this erosion of the recognition of the growing autonomy of the minor by the English courts has been reversed somewhat by the recent case of $R$ (Axon) $v$ Secretary of State for Health (Axon). ${ }^{38}$

\section{B Back to Gillick, but still a best interests approach?}

Axon had a very similar fact pattern to Gillick: a mother testing the legality of a minor receiving sexual health treatment without parental consent or knowledge. The case has been cited as possibly "reversing the retreat from Gillick" which occurred due to the above cases, as the judge, Silber J, put great emphasis on the autonomy of the minor throughout his judgment. ${ }^{39}$ Unfortunately, this emphasis was mere rhetoric, as he still advocated a best interests approach in his guidelines for health professionals to follow when assessing capacity for minors seeking sexual health advice and treatment, which mirrored Lord Fraser's approach. ${ }^{40}$

One could argue that the best interests approach, advocated by Lord Fraser and Silber J, only really changes the arbiter of what is in a child's best interests from a parent to a doctor, or to a judge (if the wardship jurisdiction is invoked); after all Mrs Gillick and Mrs Axon both acted in what they believed was the best interests of their children. ${ }^{41}$ Lord Fraser argued that a doctor may be a better

$34 \operatorname{Re} Z$ (A Minor) (Identification: Restriction on Publication) [1996] 2 FCR 164 (CA) at [170]

$35 \operatorname{Re} X[1991] 2$ NZLR 365 (HC) at [370].

36 Care of Children Act 2004, s 30.

$37 \operatorname{Re} R$ (A Minor) (Wardship: Consent to Treatment) [1991] 3 WLR 592 (CA) at [602] [Re R].

$38 R$ (Axon) $v$ Secretary of State for Health (Family Planning Association Intervening) [2006] 2 WLR 1130 (CA) at [1164] [Axon].

39 Rachel Taylor "Reversing the Retreat from Gillick? R (Axon) v Secretary for State for Health" (2007) 19 CFLQ 81 at 94.

40 Axon, above n 38, at 1177.

41 Ibid, at 1146. 
judge of medical advice and treatment than a minor's parents, ${ }^{42}$ and Lord Scarman highlighted that the welfare jurisdiction of the court could also over-ride parental beliefs of what is in the best interest of their children. ${ }^{43}$

Therefore, it could be argued that Gillick à la Lord Fraser was based on who had the best claim to know what is in the best interests of the child. In that case, it was the doctor, to the extent that the doctor could over-ride the wishes of a competent minor if the doctor believed that contraceptive advice and treatment given without parental consent or knowledge was not in the minor's best interests. $^{44}$

Although Lord Scarman did not specifically raise the issue of best interests, he stated that a doctor must use his clinical judgment and this implies that a doctor considers a minor's best interests before making a clinical decision. ${ }^{45}$ Therefore, the best interests veto of either the health professional or the court can over-ride a Gillick competent minor's decision to consent to contraception advice and treatment without parental consent and knowledge.

\section{But Minors are Still Minors}

An adult of 16 "whose mental capacity is unimpaired has the right to decide for herself whether she will or will not receive medical or surgical treatment, even in circumstances where she is likely to die in the absence of treatment". ${ }^{46}$ So should a girl of 15 years and 364 days, who is deemed wise enough to fulfil Lord Scarman's criteria, have her decision over-ruled by a doctor or a court? The issue is eloquently put by Lord Bingham MR: ${ }^{47}$

... children are human beings in their own right with individual minds and wills, views and emotions, which should command serious attention. A child's wishes are not to be discounted or dismissed simply because he is a child ... [but] the fact [remains] that a child is, after all, a child. The reason why the law is particularly solicitous in protecting the interests of children is because they are liable to be vulnerable and impressionable, lacking the maturity to weigh the longer term against the shorter, lacking the insight to know how they will react and the imagination to know how others will react in certain situations, lacking the experience to measure the probable against the possible.

42 Gillick, above n 1, at 173 per Lord Fraser.

43 Ibid, at 184 per Lord Scarman.

44 Ibid, at 174 per Lord Fraser.

45 Ibid, at 189 per Lord Scarman. Lord Donaldson explicitly said what Lord Scarman appears to imply in $R e R$ (A Minor) (Wardship: Consent to Treatment) [1991] 3 WLR 592 at [603].

46 Re T (Adult: Refusal of Treatment) [1992] 4 All ER 649 (CA); and implicit in Care of Children Act 2004, s 36 .

$47 \operatorname{Re} S$ (A Minor) (Independent Representation) [1993] 2 FLR 437 (CA) at [448]. 
This is the issue. These children, despite their maturity and intelligence, are still children and society naturally wants to protect them.

In New Zealand the legislature has recognised that children are capable of making autonomous decisions, ${ }^{48}$ but has also explicitly recognised that the welfare and best interests of the child must be the first and paramount consideration. ${ }^{49}$ New Zealand has also adopted the United Nations Convention on the Rights of the Child (UNCROC), ${ }^{50}$ which recognises and ensures States take note of the increasing autonomy of children as they mature, but also that the welfare of the child is a "primary consideration" and that guardians of children will have their best interests as their basic concern. There is a real tension between the natural protective tendencies of the international law, the legislature, the court and health professionals, and the trend to recognise minors as being in a continuum moving towards full adult autonomy. The case of Re E, discussed above, demonstrates this point by the fact that the subject of the case died at 18 after refusing to have a blood transfusion. ${ }^{51}$

A competency test for minors has been suggested where an understanding of the right to make medical decisions rather than an understanding of the medical treatment itself is tested. The test therefore removes the paternalistic veto of both health professionals and the court as it interprets article 3 of UNCROC as the best interests of the child as the child sees it, rather than guardians acting in the best interests of the child. ${ }^{52}$ Thus the courts can only intervene on the issue of whether the minor understands their rights and not the actual treatment. ${ }^{53}$ This full removal of the welfare principle, however attractive, is artificial; it does not accord with how society works. Society wants to protect minors for the simple fact that in some circumstances minors do need protection and circumstances such as described in $R e E$ would be very hard for society to swallow if the courts did

48 For example, The Children, Young Persons and their Families Act 1989, s 5(d):

The principle that consideration should be given to the wishes of the child or young person, so far as those wishes can reasonably be ascertained, and that those wishes should be given such weight as is appropriate in the circumstances, having regard to the age, maturity, and culture of the child or young person.

Also the Care of Children Act 2004, s 16(1)(c) "determining for or with the child, or helping the child to determine, questions about important matters affecting the child".

49 Care of Children Act 2004, s 4; Children, Young Persons and their Families Act 1989, s 6.

50 Office of the UN High Commissioner for HR Convention on the Rights of the Child GA Res 44/25 (1989) [UNCROC].

51 Caroline Bridge "Refusal of Medical Treatment and Court Intervention" (1995) 1 BFLJ 233 at 233.

52 UNCROC, above $\mathrm{n} 50$, article 3 .

53 Jamie Potter "Rewriting the Competency Rule for Children: Full Recognition of the Young Person as Rights Bearer" (2006) 14 JLM 74 at 74. 
not intervene to over-ride the intelligent and informed wishes of a minor. ${ }^{54}$ However, the use of the best interests principle in Lord Fraser's and Silber J's guidelines for contraception advice and treatment seems heavy-handed and disproportionate to the possible harm, and one which New Zealand should not embrace. It is therefore recommended that the best interests principle invoked by health professionals or the courts should only be used in extreme cases such as life-saving blood transfusions. Receiving contraceptive advice and treatment will very rarely fall into this category.

On a practical level, if a health professional believes it is not in a minor's best interests to be given contraceptive advice and treatment without parental consent and knowledge, then this can lead to risky sexual behaviour and the use of less effective contraceptive methods as described above. This is not a situation which should be encouraged as New Zealand's teenage pregnancy rate is higher than Australia, Canada and the United Kingdom, ${ }^{55}$ and the rate of abortion in 15-19 year olds is 26 per 1000 which is one of the highest in the world. ${ }^{56}$ These statistics do not show the side effects of teenage pregnancy such as potential loss of education and employment opportunities for these young mothers, and the potential physiological and psychological effects of abortions.

\section{THE DIFFERENCE OF PRESUMPTIONS}

Despite the problems with adopting Gillick into New Zealand law, is there a problem with the fundamental premise on which Gillick is based?

The ruling in Gillick comes from a presumption of incompetence; the minor has to prove to the assessing health professional that they are competent to make the decision on contraception without the need for parental guidance or knowledge.

New Zealand, on the other hand, follows a statutory presumption of competence for all health and disability consumers, ${ }^{57}$ this includes minors, as the legislature only limited the meaning of the

54 New South Wales Law Reform Commission Report 199: Young People and Consent to Health Care (Sydney, 2008) at 55-59 [Young People and Consent]. The Commission decided not to interfere with the welfare jurisdiction of the court in its recommendations as it felt even competent minors need protection and should be treated differently from adults due to lack of world experience and social development, however it did not specify a threshold but thought judges have enough experience to decide this.

55 Sarah Cheesbrough and others Reducing the Rate of Teenage Conceptions. A Review of the International Evidence on Preventing and Reducing Teenage Conceptions: The United States, Canada, Australia and New Zealand (Health Development Agency, London, 2002) at 11.

56 Statistics New Zealand Demographic Trends: 2007 (Wellington, 2008) at 133.

57 Health and Disability Commissioner (Code of Health and Disability Services Consumers' Rights) Regulations 1996, Sch 2, Right 7(2) "Every consumer must be presumed competent to make an informed choice and give informed consent, unless there are reasonable grounds for believing that the consumer is not competent". 
word "consumer" to an individual accessing health or disability services. ${ }^{58}$ This puts minors in the same situation as adults: their competency can be rebutted by evidence to the contrary. But does this make any legal or practical difference to the use of Gillick? In England more rights would be given to the minor as they grow in competency, in New Zealand rights would be taken away.

Potter argues that the presumption of incompetence regarding minors found in England and Australia can be justified only if a minor is legally seen as their parents' property and there is "simply too much evidence of the developing competency and abilities of young people in a variety of areas to maintain the current presumption". ${ }^{59}$ This evidential perspective is backed by the New South Wales Law Reform Commission (NSWLRC) which argues that the presumption of incompetence for minors, as that of the presumption of competence for adults, is based on intuition rather than evidence, ${ }^{60}$ and thus to deprive rights, based on such assumptions, does not accord with the developing status of minors in society.

In reality, the presumption makes little difference, as health professionals would use the same type of analysis whichever way round the presumption was, as will be discussed later, and a court would simply determine who had the burden to rebut the presumption. Therefore, the opposite presumption in New Zealand would not inhibit the adoption of Gillick.

\section{Further Obstacles to the Adoption of Gillick}

Two further issues need to be discussed in relation to whether Gillick could or should be adopted into New Zealand. First, Gillick dealt only with consent and not refusal to consent. Therefore the case law, which has subsequently ruled on this aspect, will be explored. Second, the issue of confidentiality was not directly mentioned in either Lord Scarman's or Lord Fraser's test but is an issue central to accessibility to health care services.

\section{Refusal to consent}

Lord Donaldson added a spin to the Gillick decision by his obiter dictum in Re R, where he expressed the view that Lord Scarman had not said that parents lose their right to consent if the minor refuses treatment. He believed that if a minor was deemed Gillick competent, then the minor,

58 Ibid, s 4; and Health and Disability Commissioner Act 1994, s 2 "Disability services consumer means any person with a disability ... and Health consumer includes any person on or in respect of whom any health care procedure is carried out".

59 Potter, above n 53, at 70.

60 Young People and Consent, above n 54, at 42. Although the commission presents contradictory evidence of how adolescents' decision-making capacity compares with that of adults, in some cases decisions emphasise peer acceptance, short term implications and risk taking. The evidence is unclear as to how this affects actual decision making capacity, they ask should the legal presumption really look beyond the pure cognition ability to a "broader notion of their social and emotional maturity" as with adults, the test of competence is purely the ability to use information, a cognitive test. 
as well as the parents could consent, a concurrent right to consent. Therefore, if the minor can consent the parent does not need to, but if the minor refuses to consent then the parent can consent on the minor's behalf. ${ }^{61}$

This situation is not envisaged when a minor goes to a health professional for contraceptive advice and treatment, as it is the minor that is seeking the treatment and not the health professional seeking to enforce the treatment. However, rare situations can arise where parents try to force contraception on their children in an effort to discharge their best interests duty. ${ }^{62}$

The New Zealand Bill of Rights Act 1990, s 11 (BORA), dictates "everyone has the right to refuse to undergo any medical treatment". This right is further embodied in the Health and Disability Code. ${ }^{63}$ However, Tompkins J concluded that this right did not exist for minors, basing his decision on the legal age to give effective consent or refusal of consent to medical treatment, with no regard for Gillick and increasing minor autonomy. ${ }^{64}$ Unfortunately, the judge did not elaborate when this capacity may arise. ${ }^{65}$ He would have been justified in invoking the wardship jurisdiction of the court if the boy in question had been assessed to be incapable of refusing consent rather than presenting his decision based purely on the boy's incapacity due to his age. Further the situation, although serious as the boy could lose his eyesight without the surgical intervention, was not one of life and death which had forced the English courts to deem minors incompetent, so as to be able to protect their best interests. ${ }^{66}$ McDowell argues that Tomkins J's conclusion was "illconsidered and unsubstantiated" and should therefore not reflect the law in New Zealand. ${ }^{67}$ She further believes that refusal to consent, like capacity to consent should be assessed and so if there is the capacity to consent then there is also the capacity to refuse. ${ }^{68}$

$61 \operatorname{Re} R$, above $\mathrm{n} 37$, at 601 .

62 Conversations with several general practitioners in the Wellington region, New Zealand, March 2009.

63 Health and Disability Commissioner (Code of Health and Disability Services Consumers' Rights) Regulations 1996, Sch 2, Right 7(7) "Every consumer has the right to refuse services and to withdraw consent to services".

64 Auckland Healthcare Services Ltd v Liu HC Auckland M812/96, 11 July 1996 at 7. At that time the legislative scheme controlling age of capacity to consent or refuse medical treatment was the Guardianship Act 1968 s 25, which has been replaced by Care of Children Act 2004, s 36(1).

65 Ibid. Ibid. The case concerned a boy of 12 and his parents, all of whom refused to sanction a sight-saving operation due to their religious beliefs.

67 Morag McDowell "Medical Treatment and Children: Assessing the Scope of Child's Capacity to Consent or Refuse to Consent in NZ" (1997) 5 JLM 90 at 90.

68 Ibid. 
McDowell's analysis is logical and accords with the court's comments in $\operatorname{Re} S$ that "every person" in s 11 of BORA relates to everyone who has the capacity to consent. ${ }^{69}$ This approach has been subsequently followed by Miller $\mathrm{J}$ in $K R v M R \cdot{ }^{70}$ Although both these cases concerned medical treatment of vulnerable adults, the former an intellectually disabled woman, and the latter, a man suffering from acute paranoia, the logic of the argument could equally be levelled at competent minors. However, the rights in BORA are not absolute and are subject to a "reasonable" qualification, which could be used to deny a competent minor the right on the basis of welfare. ${ }^{71}$

The illogical reasoning of Lord Donaldson's remarks has also been criticised by the Australian High Court, which could not understand why consent to medical treatment should be more powerful than a refusal to the treatment. ${ }^{72}$ Further, it is contended that Lord Donaldson's obiter comments on concurrent rights were made in the context of his exercising the court's welfare jurisdiction over a young girl whose competency fluctuated, depending on her mental state. ${ }^{73}$ His comments can be seen as part of his justification for invoking the court's wardship jurisdiction and specific to that situation, thus inappropriate to minors seeking contraceptive advice and treatment due to the nonacute nature of this medicine. Therefore, it is contended that the right to refuse medical treatment includes all those capable of exercising that right.

\section{Confidentiality}

Mrs Gillick argued that a minor could not be given contraceptive advice or treatment without a parent's consent or knowledge. ${ }^{74}$ This issue of knowledge will now be explored. This involves the laws of confidentiality and privacy with respect to medical information and whether information regarding a minor can be kept confidential against their parents.

(a) England and Gillick

$69 \operatorname{Re} S$ [1992] 1 NZLR 363 (HC) at [373] per Barker J. His comments were made in reference to the Mental Health (Compulsory Assessment and Treatment) Act 1992, s 66 "Every patient is entitled to medical treatment and other health care appropriate to his or her condition".

$70 K R v M R[2004] 2$ NZLR 847 (FC) at [860].

71 Lucy Thomson "Whose Right to Choose? A Competent Child's Right to Consent and Refuse Medical Treatment in New Zealand" (2000) 8 CLR at 173. The rights in the New Zealand Bill of Rights Act are subject to s 5, "... the rights and freedoms contained in this Bill of Rights may be subject only to such reasonable limits prescribed by law as can be demonstrably justified in a free and democratic society" and could therefore create similar situations as discussed in $\operatorname{Re} E$ and $R E L$ where refusal to consent was overridden by the best interests of the child. It is debatable, although in those cases the minors were not deemed competent, that in reality the bar was set so high that they would have been found competent if their situation were not a matter of life and death.

72 Re Marion, above $\mathrm{n}$ 11, at 458 per McHugh J, dissenting in part.

$73 \operatorname{Re} R$, above n 37, at 601 .

74 Gillick, above n 1, at 177 per Lord Scarman. 
In England, all doctors owe a legal duty of confidence to all patients, whatever the age. The courts see this as a separate duty from that of a duty of care. ${ }^{75}$ Therefore a minor, like any other patient is in a confidential relationship with their health professional. ${ }^{76}$ This duty of confidence exists against third parties and has been well established by the UK courts, but whether this duty exists against parents has not been directly decided. ${ }^{77}$

The majority law lords in Gillick did not specifically discuss confidentiality against parents. However their view was implicit, as they rejected Mrs Gillick's submissions, the second of which was that parents need to be informed of the children's medical treatment in order to perform their parental duties. Only Lord Fraser alludes to the issue, that, if his guidelines are followed, then the health professional is "justified in proceeding without the parent's consent or even knowledge". ${ }^{78}$

This raises two questions: should confidentiality be kept against parents if the minor is deemed not Gillick competent or if the minor is Gillick competent but the health professional decides it is not in their best interests to receive contraceptive advice and treatment without parental knowledge and consent?

The logical answer to both questions is yes; as Lord Fraser observed, minors "are often reluctant to confide in their parents about sexual matters". ${ }^{79}$ There is much evidence to suggest that young people are more reluctant to use sexual health services if confidentiality is not guaranteed. ${ }^{80}$ Silber J presented examples of surveys and research showing that one of the most important aspects of a sexual health service was confidentiality, and he therefore argued that, as a matter of policy, confidentiality needs to be kept. ${ }^{81}$ But has the law kept up with this social reality? After all Silber J gave health professionals a "get out clause" by allowing confidences to be broken if they deemed it in the minor's best interests ${ }^{82}$ and this has been adopted by the General Medical Counsel of Great

$75 \operatorname{Re} Z$ (A Minor) (Identification: Restrictions on Publications) [1997] Fam 1 (CA) at [25].

76 Axon, above n 38, at 1153; and Dame Elizabeth Butler-Sloss who recognised that "Children, like adults, are entitled to confidentiality in respect of certain areas of information. Medical records are the obvious example" from Venables $v$ News Group Newspapers Ltd (2001) 151 NLJ 574 (UKHL) at 574.

77 Joan Loughrey "Can You Keep a Secret: Children, Human Rights, and the Law of Medical Confidentiality" (2008) 20 CFLQ 312 at 320.

78 Gillick, above n 1, at 174 per Lord Fraser.

79 Ibid, at 173 per Lord Fraser.

80 Diane Reddy and others "Effect of Mandatory Parental Notification on Adolescent Girls use of Sexual Health Care Services" (2002) 288 JAMA 710 at 710.

81 Axon, above n 38, at 1153-1154; Taylor, above n 39, at 84, argues that Axon established that a duty of confidentiality is owed to minors who are Gillick competent, however she ignores the health professional best interests veto.

82 Axon, above n 38, at 1177. 
Britain guidelines (GMC), which says that doctors can disclose information if a child is putting themselves at risk. ${ }^{83}$

The English courts have not directly ruled on whether a confidential relationship can exist against parents but have ruled on what type of information should be confidential. The House of Lords deemed health information to be a type of information that attracts confidentiality, approving the "reasonable expectation" test of Gleeson CJ, whether the disclosure of the information would be "highly offensive to a reasonable person of ordinary sensibilities". ${ }^{84}$ However, the use of the "reasonable expectation" test can be problematic. As Loughrey argues, a health professional could use the test to justify disclosure to parents as most minors would expect their parents to be informed of their medical treatment. ${ }^{85}$

Gillick did not directly rule on confidentiality, but it can be implied that the majority decision would not make much sense if contraceptive advice or treatment could not be given without parental knowledge. Further, the policy arguments put forward by Lord Fraser and Silber J give great weight to the necessity of a confidential relationship. However, neither made direct comment on whether non-competent minors attracted confidentiality against their parents and both gave health professionals a best interests veto which questions the absolute nature of the right to confidentiality. Moreover, English case law has deemed health information confidential against a third person but made no specific comment about whether a third person includes parents.

(b) The New Zealand law

The New Zealand courts have not ruled on this issue either, but with regards to health information, have also relied on the fiduciary relationship that arises between health professional and lay person with respect to a third party to protect confidences. However, this confidence can be broken if the health professional needs to discuss the case with another medical colleague, defend themselves against accusations of wrongful conduct or if another's life is at imminent risk. ${ }^{86}$

Therefore, any disclosure of medical information against the wishes of the patient must be assessed against whether the disclosure can be justified in terms of the above criteria, but also in terms of the public interest, or in this case, the parent's interest. The public interest is defined as protecting others from imminent serious harm, prevention of a crime or other serious wrongdoing or in the interest of free speech. ${ }^{87}$ The Privacy Act 1993, which applies to minors, as they are not

83 Guidelines cited by Loughrey, above n 78, at 325.

84 Campbell v MGN Ltd [2004] 2 AC 457, at [94] (UKHL), approving Australian Broadcasting Corporation v Lenah Game Meats Pty Ltd (2001) 208 CLR 199 (HCA) per Gleeson CJ.

85 Loughrey, above n 77, at 321.

86 Duncan v Medical Disciplinary Committee [1986] 1 NZLR 513 (HC) at [521].

87 Loughrey, above n 77, at 325. 
excluded, extends this list to include disclosure "to prevent or lessen a serious and imminent threat $\ldots$ to the individual concerned". ${ }^{88}$ That would include evidence of abuse. Contraception advice and treatment will very rarely be covered by any of these criteria, and thus disclosure to parents would be totally unjustified, whether the minor was deemed competent or not.

However, the New Zealand Medical Association, also recommends a doctor can disclose information if it is clearly in the patient's best interests, which would include disclosure of a minor's health information to parents. ${ }^{89}$ This is a much lower threshold than expressed by New Zealand's case and statute law as discussed above. It is consistent with the best interests veto of the English guidelines on contraception from Axon which closely mirror Lord Fraser's guidelines, but for the fact that unlike Axon, Lord Fraser did not mention confidentiality in the final step of his guidelines, only parental consent. ${ }^{90}$

This adoption of Gillick competency for contraceptive advice and its update and reaffirmation in Axon does not accord with the social necessity of confidential access to sexual health services, nor to the criteria that New Zealand affords to the breaking of professional confidences. The paternalistic nature of the English common law dominates the confidentiality issue and under that regime a health professional can be justified in breaking confidence to parents if that professional believed it was in the minor's best interests.

New Zealand's legislation appears to have divided the issues of welfare and confidentiality so that confidentiality will only be broken in very serious circumstances, whereas the best interests of the minor is a clinical judgment for the health professional and ultimately the courts. Therefore a Gillick competent minor should be afforded a confidential consultation, unless there are real hazards posed. This accords with the recent report from the NSWLRC which decided that, if a minor is competent to consent, then a parent has no powers of consent regarding the child in that situation and so should not have the power to obtain their confidential medical information. ${ }^{91}$

The NSWLRC further stated that, in order for a parent to fulfil their welfare duty towards the minor if that minor has not been deemed competent, the health professional does not owe a duty of confidentiality to the minor. ${ }^{92}$ Loughrey argues against this view; a right to confidentiality must be recognised even if the child is not competent to make a decision regarding medical treatment, as

88 Privacy Act 1993, s 6, principle 10 and Privacy Commissioner Health Information Privacy Code 1994: Incorporating Amendments and Including Revised Commentary (New ed, Privacy Commission, Wellington, 2008) at r 11(2)(d).

89 New Zealand Medical Association Code of Ethics: For the New Zealand Medical Profession (New Zealand Medical Association, Wellington, 2008) at 7.

Gillick, above n 1, at 174 per Lord Fraser.

91 Young People and Consent, above n 54, at 24

92 Ibid. 
children will not feel safe accessing health care and health professionals may not take children's views into account. ${ }^{93}$

The author recognises the logic of the NSWLRC, but from a policy stance favours Loughrey's perspective. This stance also accords with UNCROC, that a child should have full access to health services. ${ }^{94}$ Sexual health can be a deeply personal and embarrassing area for anyone, especially minors; if they felt there was a risk that a consultation was not going to be confidential this would dissuade them from approaching sexual health services and may promote risky sexual behaviour. The only caveat to this position is, if keeping the confidentiality will cause serious and imminent harm to the individual or another, in accordance with New Zealand's privacy laws.

\section{THE COMPETENCY TEST FOR CONSENT TO CONTRACEPTIVE ADVICE AND TREATMENT}

The majority Gillick judgments have created debate as to whether the competency tests go towards a capacity to understand or an actual understanding of the proposed treatment. This will be discussed and recommendations made. Further, an attempt will be made to formulate a threshold for the competency test, which Lord Fraser left open, but which was too high in Lord Scarman's test.

\section{A Capacity to Understand or Actual Understanding}

Both Lord Fraser's and Lord Scarman's tests allow for differing interpretations of what is meant by "understanding". There is academic debate whether "understanding" should be interpreted as a capacity to understand or as an actual understanding of the proposed treatment. ${ }^{95}$ In step one of Lord Fraser's guidelines he does not qualify "understand", although earlier in his speech he qualified his test with whether the minor is "capable of understanding what is proposed, and of expressing his or her own wishes". 96 Although this qualification could silence the debate regarding Lord Fraser's test, the ambiguity remains as the understanding goes to the specific proposal, in that case of contraceptive advice and treatment.

93 Loughrey, above n 77, at 319.

94 Office of the UN High Commissioner for HR Convention on the Rights of the Child GA Res 44/25 (1989), article 24:

States Parties recognize the right of the child to the enjoyment of the highest attainable standard of health and to facilities for the treatment of illness and rehabilitation of health. States Parties shall strive to ensure that no child is deprived of his or her right of access to such health care services.

95 For example Leanne Bunney "The Capacity of Competent Minors to Consent to and Refuse Medical Treatment" (1997) 5 JLM 52 at 52 argues that Gillick represents a capacity based test, whereas Paul Biegler and Cameron Stewart "A Primer on the Law of Competence to Refuse Medical Treatment" (2004) 78 ALJ 325 at 333 interpret the Gillick tests as actual understanding of the treatment.

96 Gillick, above n 1, at 169 per Lord Fraser. 
Similarly, Lord Scarman's test describes an actual understanding, "to understand fully what is proposed". ${ }^{97}$ But he echoes this test earlier in the judgment, that a minor can make "decisions when he reaches a sufficient understanding and intelligence to be capable of making up his own mind". ${ }^{98}$ which falls into the capacity camp. However, it can be argued that this was a general comment about development of minors and not addressed to the specific question of contraception advice and treatment. Further, the qualification of his test, as discussed above, tends to suggest an actual understanding of the proposed treatment, as the minor must "fully" understand specifics of the treatment.

The imprecision in the language of the judgment is capable of alternative interpretations and does not give sufficient guidance as to how the minor should be assessed by the health professional. However, if the capacity to understand approach is used, then the competency assessment and the making of an effective consent become two separate questions. ${ }^{99}$

In New Zealand this separation would be artificial, as capacity to understand and actual understanding of the proposed treatment would be blurred. This is due to the presumption of competence of all health consumers to be able to consent to treatment and the duty of health professionals to fully inform the consumer according to that consumer's circumstances, so an effective consent can be ascertained. ${ }^{100}$ Thus an adult and minor alike are presumed competent unless rebutted by evidence and an effective consent is only possible when they have been fully informed to make a decision. Therefore, a health professional would test the ability of the minor to make a decision based on the information given by that health professional, to ensure an informed decision and this would thus test the understanding of the actual treatment, rather than test the general capacity of the minor. This reasoning can be illustrated by the general common law competency test, the "...ability to understand the nature and quality of the relevant transaction". ${ }^{101}$ Although the word "ability" is used, suggesting a capacity approach, the test is situation specific as it refers to the "relevant transaction", and so refers to actual understanding of a proposal. ${ }^{102}$

97 Ibid, at 189 per Lord Scarman.

98 Ibid, at 187 per Lord Scarman.

99 Bunney, above n 95, at 59.

100 Health and Disability Commissioner (Code of Health and Disability Services Consumers' Rights) Regulations 1996, Sch 2, Right 6(2): "Before making a choice or giving consent, every consumer has the right to the information that a reasonable consumer, in that consumer's circumstances, needs to make an informed choice or give informed consent."

$101 \operatorname{Re} M M($ An Adult) [2008] 3 FCR 788 (FC) at [807].

102 Ibid, at 814. In this case a mentally vulnerable adult was deemed to be capable of understanding the nature and consequences of sexual intercourse but not capable of understanding with whom she should have social contact. 
It is submitted that the tests and speeches of Lord Scarman and Lord Fraser tend towards an actual understanding of the proposed contraceptive treatment and the practical reality of the competency assessment dictates that the competency test should go towards an actual understanding of the proposed treatment, rather than a capacity to understand the proposed treatment. Although there is a danger that a minor's understanding could be judged on flawed information given by the health professional, ${ }^{103}$ reliance on the actual understanding approach allows minors to be assessed for each situation and thus helps protect the autonomy of the minor, rather than a static capacity approach.

\section{$B$ The Threshold of Understanding}

Lord Fraser left the threshold of understanding, required to be deemed competent to consent to contraceptive advice and treatment without parental knowledge or consent, open in his guidelines and Lord Scarman's "wise choice" has been argued to be too high. Therefore, what should the actual threshold of the competency test be? The suitability of tests from New Zealand and other jurisdictions will be discussed and recommendations made as to what is considered the most suitable.

Several jurisdictions have made attempts to legislate specific guidelines for determining minor competency to consent to medical treatment, such as South Australia and British Columbia. The South Australian legislation uses the threshold "capable of understanding the nature and consequences of the treatment". ${ }^{104}$ This threshold is similar to the common law competency test described above, as is that of British Columbia which also uses the South Australian standard but includes "reasonable foreseeability" with respect to the benefits and risks of the proposed treatment. ${ }^{105}$ This threshold can be construed as including elements of Lord Scarman's qualification, as the "nature" of the treatment can include the moral and ethical elements of treatment; a threshold which, it has been argued, is unsuitable with regards to contraceptive advice and treatment.

New Zealand has no legislation specifically describing the threshold of minor consent to medical treatment, but the Protection of Personal Property Rights Act 1988 (PPPR Act) uses a formulation very similar to that of British Columbia as described above. ${ }^{106}$ Similar, also, to the

103 Part of the flawed reasoning in $\operatorname{Re} L$, above $\mathrm{n} 33$, at 527, was that information was withheld from the minor for her own good, and this was then a basis of a finding of incompetency.

104 Consent to Medical and Dental Treatment Act 1984 (SA), s 6(2)(a). The Consent to Medical Treatment and Palliative Care Act 1995 (SA), s 12(a)(i) also includes an understanding of the risks. These Australian statutes were primarily constructed to be used as defences by health professionals against claims of assault, Young People and Consent, above n 54, at 9 and 129.

105 Infants Act 1996 (BC), s 17(3)(a) "has been satisfied that the infant understands the nature and consequences and the reasonably foreseeable benefits and risks of the health care".

106 Protection of Personal Property Rights Act 1988, s 5 Presumption of competence: 
common law competency test, it starts from a presumption of competence and concerns adults in vulnerable situations. Although the test is for vulnerable adults, minors can be seen to be in a similar situation. Under the PPPR Act statutory coercive powers restrict mentally disadvantaged people. ${ }^{107}$ Similarly parents have coercive powers over their children. A further example of the similarity is explicit in the recent amendment to the Family Courts Act 1980 where the meaning of vulnerable persons and the meaning of children was amalgamated at the select committee stage $\mathrm{e}^{108}$ to encompass the group of people who would be at risk from publication of Family Court particulars. $^{109}$

Again, though, in the PPPR Act, the minor would be required to understand the "nature" of the proposed treatment, the standard maintained is too high. However, Miller $\mathrm{J}$ interpreted this legislation as "understanding of relevant information". ${ }^{110}$ The UK equivalent of the PPPR Act, which focuses on mental capacity of adults, has a similar list of considerations but instead of "nature" the test also goes to an understanding of information "relevant" to the decision and the "reasonably foreseeable consequences of deciding one way or another, or failing to make the decision". 111 This formulation is also used in the capacity test for generic health consumers, which includes minors, in the jurisdictions of Prince Edward Island and Ontario ${ }^{112}$ and recommendations of the Law Commissions of New South Wales and England and Wales. ${ }^{113}$

For the purposes of this Part of this Act, every person shall be presumed, until the contrary is proved, to have the capacity-

(a) To understand the nature, and to foresee the consequences, of decisions in respect of matters relating to his or her personal care and welfare; and

(b) To communicate decisions in respect of those matters.

107 Law Commission Report 80: Protections some Disadvantaged People May Need (NZLC R80, 2002) at 613.

108 Family Courts Matters Bill 2008 (143-2) cl 11D. Clauses 11D Meaning of child and 11E Meaning of vulnerable person were amalgamated into the final subsection $11 \mathrm{D}$.

109 Hon J Turner (15 April 2008) 646 NZPD 15687.

$110 K R v M R$, above $\mathrm{n} 70$, at 857:

It has been held that four factors are particularly important in determining whether a person has capacity to make the relevant decision: ability to communicate choice; understanding of relevant information; appreciation of the situation and its consequences; and manipulation of information - in other words, the person's ability to follow a logical sequence of thought in order to reach a decision.

111 Mental Capacity Act 2005 (UK), s 3.

112 Health Care Consent Act 1996 (On), s 4(1):

A person is capable with respect to a treatment, admission to a care facility or a personal assistance service if the person is able to understand the information that is relevant to making a decision about the treatment, 
This threshold requires an understanding of the relevant information of the treatment being offered and the reasonably foreseeable consequences of that treatment. The threshold, therefore, prevents an investigation into moral and familial questions, which have little relevance to the minor's capacity. Instead, it focuses more on a realistic cognitive ability to comprehend the information given by the health professional under their duty to facilitate an informed choice. The reasonable foreseeability component also accords with the sliding scale approach of Gillick, that with the increasing gravity of the procedure the greater the appreciation the minor must have of the consequences of a decision. It is therefore submitted that this threshold is most appropriate for determining if a minor has understood the proposed treatment.

\section{CONCLUSIONS AND RECOMMENDATIONS}

An adoption of Gillick competency into the determination of whether a minor can receive contraceptive advice and treatment without parental consent or knowledge has a myriad of problems. A recent Australian study demonstrated what the situation in New Zealand could be if Gillick was adopted without consideration. The study showed that general practitioners had no real understanding of how to assess a minor's competence for contraceptive advice and treatment and as such there was much variation between criteria to judge competence and the threshold needed to obtain competence and thus large variations in outcomes. ${ }^{114}$

Perhaps more indicative is the fact that Australian law is yet to consistently apply Gillick even though it was adopted in 1992 and in 2008 the NSWLRC recommended clear legislative guidelines in the sphere of child consent to medical treatment. ${ }^{115}$ In the search for clarity, it is feared that

admission or personal assistance service, as the case may be, and able to appreciate the reasonably foreseeable consequences of a decision or lack of decision.

Consent to Treatment and Health Care Directives Act 1988 (PEI), s 7(1):

(1) Capacity with respect to treatment

(a) to understand the information that is relevant to making a decision concerning the treatment;

(b) to understand that the information applies to his or her particular situation;

(c) to understand that the patient has the right to make a decision; and

(d) to appreciate the reasonably foreseeable consequences of a decision or lack of a decision.

Both legislation refers to health consumers of any age and from a starting point of a presumption of capacity.

113 Young People and Consent, above n 54, at 126; and Law Commission of England and Wales Mental Incapacity Report No. 231 (London, 1995) at 38.

114 Terence Bartholomew and Tatiana Carvallo "General Practioners' Competence and Confidentiality Determinations with a Minor who Requests the Oral Contraceptive Pill" (2005) 13 JLM 191 at 202.

115 Young People and Consent, above n 54, at 60. 
doctors in New Zealand may take the pragmatic approach of falling back on patriarchal ethics of what they deem is in the best interests of the child, rather than actually determining if the minor has capacity to consent to the proposed treatment.

The majority judgment in Gillick is a most appropriate basis when considering a competency framework for minors regarding contraception advice and treatment. This basis has been likened to a sliding scale, ${ }^{116}$ what Judge Somervile called a "continuum" upon which the duties and rights of guardians fall, depending on the minor's capacity to understand and the complexity of the issues. ${ }^{117}$ A good example of this is $R e R$ where the complexity of the treatment of a blood transfusion was low, but the risks to life of not having it were very high, so a very high level of competency was required of the minor. ${ }^{118}$ The sliding scale idea has already been adopted by New Zealand statute, as the duties of guardians include "determining for or with the child, or helping the child to determine, questions about important matters affecting the child", ${ }^{119}$ which recognizes the developing maturity and understanding of minors, which was central to the majority judgment in Gillick.

It is concluded that Lord Scarman's test should not be used for determining capacity for minors seeking contraceptive advice and treatment without parental consent or knowledge, as his "wise choice" qualification creates too high a cognitive threshold and weighs heavily on moral and ethical issues.

Lord Fraser's guidelines are seen as a better option but the best interests veto of the assessing health professional in step five of Lord Fraser's guidelines needs to be qualified. It is recommended that the veto only be used in the most extreme of cases of serious health risk. Continuing from the best interests veto is the question of confidentiality. It is recommended that, in order to promote access to sexual health care services for minors, confidentiality be kept even if the minor is deemed incompetent to consent. Confidentiality, like the best interests veto, should only be broken in the most extreme of circumstances as outlined by the Privacy Act 1993 and the common law of New Zealand, in situations of serious and imminent harm to the individual or others.

A one-size fits all competency test has been described as the "search for a holy grail", ${ }^{120}$ but with regards to contraceptive advice and treatment it is recommended that the competency test go towards an actual understanding of the proposal and the threshold for understanding go towards

116 Potter, above n 53, at 74 .

$117 M v F[2008]$ NZFLR 816 (FC) at [827].

$118 \operatorname{Re} E$, above n 30, at 224 .

119 Care of Children Act 2004, s 16(1)(c).

120 Roth and others "Tests of Competency to Consent to Treatment" (1977) 134 Am J Psch 279 at 283 cited in Potter, above n 53, at 84 . 
information relevant to making the decision and the "reasonably foreseeable" consequences of making that decision.

It is recommended that the competency test set out in the Appendix, for minors to consent to contraception advice and treatment without parental consent or knowledge, become part of the Care of Children Act 2004. The guidelines which follow the competency test are recommended for uptake by the New Zealand Medical Council. 


\section{APPENDIX}

\section{Legislation}

Section 36A Consent to contraception advice and treatment for children under 16 years of age

(1) An effective consent is required for a health professional to give contraceptive advice and treatment to a child under the age of 16 .

(2) An effective consent must be given by a guardian of the child, or the child.

(3) An effective consent by the child terminates the right of the guardian to make the decision for the child.

(4) In respect of a child under the age of 16, an effective consent or refusal to consent to contraceptive advice and treatment has the effect as if the child were of full age.

(5) The validity of an effective consent or refusal to consent is subject to the inherent jurisdiction of the High Court and the wardship jurisdiction of the Family and High Court under section 30 of this Act, if the decision by the guardian or the child will cause serious risk of harm to the child's physical or mental health.

(6) The child has a full right to confidentiality whether the child is able or unable to give an effective consent or refusal to consent, subject to exceptions in the Privacy Act 1993.

(7) For the purposes of subsection (3), consent is effective if the child:

(a) understands the information relevant to making a decision on contraception; and

(b) appreciates the reasonably foreseeable consequences of their decision.

\section{Professional Guidelines}

For a health professional to give contraceptive advice and treatment to a child under 16 years without parental consent and knowledge:

(1) The health professional must be satisfied that the minor is able to understand the information relevant to making a decision on whether to accept or reject contraception advice and treatment; and

(a) This will be assessed by questions that demonstrate that the minor understands the information that the health professional has provided and can reasonably foresee the consequences of that decision. The information a health professional gives a minor must be at a level to allow the minor to be able to make an informed choice. Examples 
of questions to be asked after the health professional has given the child the relevant information include: ${ }^{121}$

i. $\quad$ Please can you tell me the purpose of contraception, what are the benefits and risks of taking and not taking contraception?"

ii. "Could you please tell me the alternative methods of contraception I have explained to you?"

iii. "Please tell me which you believe is the most appropriate form of contraception for you, and how you reached this decision (especially if the choice differs from the health professional's recommendation)?"

(2) The health professional must be satisfied that the minor is very likely to begin or to continue having sexual intercourse with or without contraceptive treatment.

"Do you believe that you do actually need contraception advice and treatment?"

(3) The health professional should attempt to persuade the minor to involve a guardian in the decision. A decision not to involve a guardian must be respected in terms of confidentiality of the minor's consultation, irrespective of whether the minor has been assessed as competent or not. Confidentiality can only be broken if there is risk of serious and imminent harm to the minor or another member of the public, or if the health professional needs to converse with a colleague or defend themselves in a court of law.

(4) The health professional can look to the minor's best interests only if the decision the minor has made will cause serious risk of harm to the minor's physical or mental health. This will include contra-indications of treatment such as personal medical history and current medication.

121 Questions partly adapted from Paul Biegler and Cameron Stewart "A Primer on the Law of Competence to Refuse Medical Treatment" (2004) 78 ALJ 325 at 342. 
